\title{
Perfil do acompanhante durante $o$ adoecimento de crianças e adolescentes com câncer
}

\section{Caregiver profile during the process of illness in children and adolescents with cancer}

\section{Perfil del cuidador durante el proceso de enfermedad de niños y adolescentes con cáncer}

\author{
Hellen Francine Bruno Bulcão' 1 \\ Jayne Matos de Alcântara² ${ }^{2}$ \\ Layse Matos Rebouças Mota ${ }^{3}$ (1)
}

\section{Larissa de Oliveira Barbosa 4 (1) Priscila Correia da Silva Ferraz ${ }^{5}$ (1)}

\begin{abstract}
RESUMO | INTRODUÇÃO: O cuidado parental de uma criança ou adolescente em tratamento antineoplásico expõe os pais ou responsáveis a maiores responsabilidades. Essas alterações afetam as relações familiares, da vida pessoal, do trabalho e até mesmo na própria relação de pais e filhos. OBJETIVOS: Descrever o perfil e a participação do acompanhante de crianças e adolescentes com câncer em uma casa de apoio. MATERIAIS E MÉTODOS: Trata-se de um estudo transversal com abordagem quanti/qualitativa do tipo descritivo. Foram incluídos no estudo acompanhantes de ambos os sexos, com idade superior a 18 (dezoito) anos e excluídos os acompanhantes que demonstraram apresentar algum déficit cognitivo, de linguagem e/ou dificuldade de compreensão. A coleta de dados foi realizada através do uso de um questionário com os acompanhantes no período de outubro de 2019 a janeiro de 2020. RESULTADOS: A amostra do estudo foi constituída por 12 acompanhantes, sendo 11 do sexo feminino, idade média de 36,33 $\pm: 24,95$ anos, dos quais 8 (67\%) eram solteiros, relataram serem os pais das crianças/adolescentes, possuírem outros filhos e pelo menos um destes residirem com eles, a maioria deles, 25\%, possui mais de 3 filhos, $17 \%$ possuem 2 filhos e $8 \%$ apenas 1 filho. CONCLUSÃO: Com a necessidade de deixar o emprego para cuidar da criança, a maioria dos acompanhantes não desempenha nenhum tipo de ocupação. Como residem distante da unidade de atendimento, a oportunidade de permanecer numa casa de apoio facilita o acesso ao tratamento.
\end{abstract}

PALAVRAS-CHAVE: Oncologia. Pediatria. Acompanhantes. Cuidado.

ABSTRACT | INTRODUCTION: Parental care for a child or adolescent under antineoplastic treatment exposes parents or guardians to greater responsibilities required by this. These changes affect family relationships, personal life, work, and even the relationship of parents and children. OBJECTIVES: To describe the profile and participation of the family caregiver of children and adolescents with cancer in a support home. METHODS: This is a cross-sectional study with a quantitative/qualitative approach of a descriptive type. Caregivers of both sexes, over the age of 18 (eighteen) years, were included in the study, and caregivers who demonstrated some cognitive, language, and/or difficulty in understanding were excluded. Data collection was carried out using a questionnaire with the caregivers from October 2019 to January 2020. RESULTS: The study sample consisted of 12 caregivers, 11 of whom were female, mean age $36.33 \pm: 24.95$ years, of whom 8 (67\%) were single, reported being the parents of the children/adolescents, have other children and at least one of them lives with them, most of them $25 \%$ have more than 3 children, $17 \%$ have 2 children and $8 \%$ only 1 child. CONCLUSION: With the need to leave the job to take care of the child, most caregivers do not perform any occupation. As they live far from the care unit, the opportunity to stay in a support home facilitates access to treatment.

KEYWORDS: Oncology. Pediatrics. Caregivers. Care. 
RESUMEN | INTRODUCCIÓN: El cuidado parental de un niño o adolescente en tratamiento contra el cáncer expone a los padres o tutores a mayores responsabilidades que este requiere. Estos cambios afectan las relaciones familiares, la vida personal, laboral e incluso la relación entre padres e hijos. OBJETIVOS: Describir el perfil y participación de acompañantes de niños y adolescentes con cáncer en un hogar de apoyo. MATERIALES Y MÉTODOS: Se trata de un estudio transversal con un enfoque descriptivo cuantitativo / cualitativo. Se incluyó en el estudio a acompañantes de ambos sexos, mayores de 18 (dieciocho) años, y se excluyó a los acompañantes que demostraran algún déficit cognitivo, de lenguaje y / o dificultad de comprensión. La recolección de datos se realizó mediante el uso de un cuestionario con acompañantes desde octubre de 2019 a enero de 2020. RESULTADOS: La muestra de estudio estuvo conformada por 12 acompañantes, 11 mujeres, edad media 36,33 \pm : 24,95 años, de los cuales 8 (67\%) eran solteros, reportaron ser padres de niños / adolescentes, tener otros hijos y al menos uno de ellos viviendo con ellos, la mayoría de ellos 25\% tiene más de 3 hijos, 17\% tiene 2 hijos y $8 \%$ solo 1 hijo. CoNCLUsıón: Ante la necesidad de dejar el trabajo para cuidar al niño, la mayoría de los cuidadores no tienen ningún tipo de ocupación. Como viven lejos de la unidad de servicio, la oportunidad de permanecer en un hogar de apoyo le facilita el acceso al tratamiento.

PALABRAS CLAVE: Oncología. Pediatría. Cuidador. Cuidado.

\section{Introdução}

O câncer infanto-juvenil corresponde a um grupo de várias doenças que têm em comum a proliferação descontrolada de células anormais que podem ocorrer em qualquer lugar do organismo, possuindo características que o diferem do câncer em adultos (Duarte et al., 2012). Dentre elas temos a origem, predominantemente, de células embrionárias, curto período de latência e, em geral, crescimento rápido. Os principais tumores encontrados em pacientes infantis são os hematológicos (leucemias e linfomas) e os sólidos como o do sistema nervoso central, tumores ósseos, abdominais e os tumores de partes moles (Ministério da Saúde, 2019).

A taxa de incidência de câncer em crianças e adolescentes tem aumentado progressivamente ao longo do tempo. No Brasil, para o ano de 2018, o Instituto Nacional do Câncer estimou 12.500 novos casos de câncer infanto-juvenil e 2.704 mortes. Em todo o mundo, segundo a Agência Internacional de Pesquisa em Câncer (IARC), estima-se que são diagnosticados todos os anos 215.000 casos em crianças menores de 15 anos e cerca de 85.000 em adolescentes com faixa etária entre 15 a 19 anos (Instituto Nacional do Câncer, 2021).

O câncer infanto-juvenil apresenta sinais e sintomas inespecíficos, que na maioria das vezes, confundem-se com doenças comuns da infância, o que consequentemente leva a um atraso no seu diagnóstico. $O$ tratamento quimioterápico oferece a possibilidade de cura ou mesmo de ação paliativa, contudo faz com que o paciente sofra vários efeitos colaterais que causam incômodos sendo os mais frequentes apatia, perda de apetite, perda de peso, alopecia, hematomas, náuseas, vômitos e diarreia (Cicogna et al., 2010). Estas situações exigem da criança/ adolescente e de seus acompanhantes, que na maioria das vezes é a própria família, mudança de hábitos que adequem sua rotina ao enfrentamento de problemas, minimizando assim os efeitos da doença e do tratamento (Ministério da Saúde, 2019).

O cuidado parental de uma criança ou adolescente em tratamento antineoplásico expõe os pais ou responsáveis a maiores responsabilidades, como administração da medicação, internações, intercorrências até os retornos ambulatoriais e o acompanhamento em consultas e exames invasivos, onde, na maioria dos casos, são as mães que se responsabilizam pelos inúmeros cuidados. Por conseguinte, quando se percebem diante de um membro doente, pode-se constatar que muitas alterações ocorrem na estrutura familiar (Kohlsdorf \& Costa, 2011). Essas alterações afetam as relações familiares, da vida pessoal, do trabalho e até mesmo na própria relação de pais e filhos, pois eles estão vivenciando uma nova fase de descobertas e inseguranças, onde o principal foco é a preservação da vida (Duarte et al., 2012).

O Brasil possui entidades filantrópicas com o objetivo de oferecer suporte aos pacientes com câncer e suas famílias. Um exemplo de entidade filantrópica são as Casas de Apoio à Criança com câncer, que oferecem a oportunidade de tratamento especializado, quando o paciente não necessita de internação hospitalar, caracterizando uma terapêutica ambulatorial. A possibilidade de se hospedar numa casa de apoio facilita o acesso da criança ao tratamento, pois, em muitos casos, as famílias não têm condições financeiras para viagens e hospitalizações (França et al., 2017). 
A participação dos acompanhantes durante o processo de adoecimento, apesar de ser debatida em vários artigos, carece de maior exposição na área de oncologia pediátrica. Conhecer a participação dos acompanhantes dessas crianças pode trazer contribuições significativas para ajustes e/ou fortalecimento das políticas públicas para estas e seus familiares que, em sua grande maioria, vêm de condições de muita vulnerabilidade econômica e social, trazendo aos profissionais de saúde e familiares maior clareza quanto à importância dessa participação no atendimento. Diante do exposto, este trabalho tem como objetivo descrever o perfil e a participação dos acompanhantes de crianças e adolescentes com câncer durante o processo de adoecimento em uma casa de apoio.

\section{Materiais e métodos}

Trata-se de um estudo transversal com abordagem quanti/qualitativa do tipo descritivo. O público alvo foi composto por acompanhantes de crianças e adolescentes hospedados e atendidos no grupo de apoio à criança com câncer (GACC-BA), onde a população diária é representada por uma média de 40 pessoas, somando acompanhantes e pacientes. Sendo respeitados os aspectos éticos, seguindo a Resolução $n^{\circ}$ 466/12 do Conselho Nacional de Saúde (CNS), todos os indivíduos foram convidados a participar voluntariamente da pesquisa e assinaram o termo de consentimento livre e esclarecido (TCLE).

O GACC- BA é uma associação civil sem fins lucrativos, filantrópica, que assiste a crianças e adolescentes oriundos de famílias com desfavorável situação econômica, educacional e cultural, sendo a maioria delas proveniente do interior do estado. Esta assistência se dá através de uma equipe multidisciplinar composta por: assistentes sociais, fisioterapeutas, nutricionistas, psicólogos, odontólogos e voluntários. O GACC- BA também possui áreas de lazer, como brinquedoteca, sala de música e informática buscando assim proporcionar as condições necessárias para estas crianças e adolescentes serem submetidas ao tratamento adequado no combate ao câncer e ao mesmo tempo garantir qualidade de vida.
A amostra foi definida probabilística do tipo estratificada para agrupamento dos gêneros. Sendo incluídos no estudo 12 acompanhantes de ambos os sexos, com idade superior a 18 (dezoito) anos e que aceitaram participar da pesquisa. Foi utilizado como critério de exclusão os acompanhantes que demonstraram apresentar algum déficit cognitivo, de linguagem e/ou dificuldade de compreensão.

O instrumento utilizado na pesquisa foi um questionário elaborado pelas próprias autoras, semiestruturado, contendo 23 perguntas. Sendo 14 objetivas e 9 subjetivas, organizadas em três eixos norteadores, composto pela: identificação do acompanhante, conhecimentos deste acerca do câncer, participação do acompanhante no tratamento. E para calibração do instrumento foi realizado um estudo piloto no mês de setembro de 2019 com a participação de 3 acompanhantes, proporcionando ajustes na estrutura de duas questões e acréscimo de mais uma devido dificuldade de entendimento dos entrevistados. Além disto, foi possível observar qual a melhor forma de abordar este acompanhante durante a entrevista e facilitar a compreensão do mesmo.

A coleta iniciou-se no mês de Outubro com conclusão em janeiro de 2020, sendo realizada por meio de entrevista no GACC-BA, sob supervisão da fisioterapeuta responsável pelo setor, nos quartos dos pacientes (vale ressaltar que o quarto é individual ao paciente e seu acompanhante, trazendo assim sigilo nas informações que foram repassadas e para que o entrevistado se sinta mais à vontade), por apenas um dos pesquisadores, com duração média de 20 (vinte) minutos nos turnos matutino e vespertino.

A entrevista procedeu-se da seguinte forma: foi realizada a leitura do TCLE e do questionário antes de ser iniciada; permaneceu no quarto somente a fisioterapeuta, a entrevistadora e o acompanhante sendo denominado como pai ou mãe e identificados por nome de flores para preservação da sua identidade. A entrevista foi gravada em áudio durante toda a coleta, utilizando o celular IPHONE 6 e posteriormente transcrita pelos pesquisadores. 
As variáveis categóricas foram apresentadas em frequência absoluta e relativa, e as numéricas, em média e desvio padrão. E, os dados, armazenados no software Microsoft Excel 2007 e analisados através do software SPSS (Statistical Package for the Social Sciences) for Windows (versão 22).

Os dados foram transcritos considerando a comunicação oral e não oral. Segundo a análise de um filósofo francês, "O não-dito só pode ser alcançado através do que ele chama de "exterior específico" (p.149), e que posteriormente denomina de Condições de Produção do Discurso. Para este autor, o não-dito é a definição de uma ausência específica daquilo que está presente em outro lugar" (Gomes, 2015).

\section{Resultados}

A amostra do estudo foi constituída por 12 acompanhantes, sendo 11 do sexo feminino e 1 do sexo masculino, idade média de $36,33 \pm: 24,95$ anos, dos quais 8 (67\%) eram solteiros, relataram serem os pais das crianças/adolescentes, possuírem outros filhos e pelo menos um destes residirem com eles, a maioria deles $25 \%$ possuem mais de 3 filhos, $17 \%$ possuem 2 filhos e $8 \%$ apenas 1 filho.

Tabela 1. Variáveis dos acompanhantes em relação a escolaridade, ocupação e renda. Salvador-BA, 2020

\begin{tabular}{|c|c|c|}
\hline Variáveis & $\mathbf{f}$ & $f(\%)$ \\
\hline \multicolumn{3}{|l|}{ Escolaridade } \\
\hline $\begin{array}{l}\text { Ensino } \\
\text { Fundamental } \\
\text { incompleto }\end{array}$ & 7 & $58 \%$ \\
\hline $\begin{array}{l}\text { Ensino médio } \\
\text { completo }\end{array}$ & 3 & $25 \%$ \\
\hline $\begin{array}{l}\text { Ensino médio } \\
\text { incompleto }\end{array}$ & 2 & $17 \%$ \\
\hline \multicolumn{3}{|l|}{ Ocupação } \\
\hline Trabalha & 2 & $17 \%$ \\
\hline Não trabalha & 10 & $83 \%$ \\
\hline \multicolumn{3}{|l|}{ Renda familiar } \\
\hline $\begin{array}{l}\text { Sem renda } \\
\text { declarada }\end{array}$ & 2 & $17 \%$ \\
\hline$\leq 1 \mathrm{SM}$ & 7 & $58 \%$ \\
\hline$>1 \mathrm{SM}$ & 3 & $25 \%$ \\
\hline & $n=12$ & $100 \%$ \\
\hline
\end{tabular}

Legenda: $\mathrm{f}=$ frequência absoluta; $\mathrm{f}(\%)$ = frequência relativa;

SM: Salário mínimo

Fonte: As autoras (2020)

O tratamento do câncer requer gastos financeiros e o acompanhante diretamente envolvido necessita deixar seu emprego para cuidar da criança, como foi identificado neste estudo, 83\% dos acompanhantes não estão desempenhando uma ocupação nesse momento e consequentemente $58 \%$ dos participantes possuem renda familiar menor ou igual a 1 salário mínimo. Ao considerar o nível educacional dos acompanhantes, a maioria possui ensino fundamental incompleto (58\%), (25\%) possuem ensino médio completo e (17\%) ensino médio incompleto.

Tendo como referência a distância entre a cidade que residem e a casa de apoio localizada no município de Salvador, observou-se que a cidade mais próxima estava a $56 \mathrm{~km}$ e encontrava-se na região metropolitana de Salvador e a mais distante, a $886 \mathrm{~km}$, no extremo oeste da Bahia com uma média de distância 474,42 $\pm: 849,08 \mathrm{~km}$. O tempo de duração de hospedagem na casa de apoio foi de no mínimo 2 meses e máximo de 3 anos, das quais $8(67 \%)$ relataram ser a primeira vez que se hospedaram na casa de apoio e 4 (33\%) não souberam quantificar o número de vezes. 
Em relação à fase do tratamento, $3(25 \%)$ crianças realizam quimioterapia de manutenção, 7 (58\%) são submetidos a quimioterapia de altas doses e destes, 1 realiza radioterapia associada e 2 (17\%) encontram-se em cuidados paliativos. Referente a localização dos tumores, a predominância é no Sistema Nervoso Central onde foram identificados 4 (33\%) casos, 1 (8,33\%) fígado, $1(8,33 \%)$ pelve, $1(8,33 \%)$ bexiga e próstata, 2 (17\%) pulmão, 1 (8,33\%) tórax, 1 (8,33\%) região lombossacral e 1 (8,33\%) pescoço.

Ao serem questionadas quanto ao significado que a palavra câncer os revela, foi possível verificar os sentimentos que surgem ao acompanhar essas crianças/ adolescentes e a dificuldade de entender o que vai acontecer após o diagnóstico. Medo, tristeza e dor foram os sentimentos verbalizados com maior frequência, além de demonstrarem comportamentalmente através do franzir a testa, entrelaçar os dedos e choro.

No começo era difícil né, entender o que era câncer. Assim, no primeiro momento foi difícil aceitar e saber né. Até eu entender o que era câncer, foi difícil, mas depois... Assim, câncer para mim é uma palavra forte que até eu entender o que era câncer, saber o significado foi difícil. (Girassol)

Na revelação do diagnóstico do câncer infantil, o medo da morte e perda rápida da criança foi presente na fala de Girassol. E, é possível perceber, que os acompanhantes acabam negando essa possibilidade de morte, para si e para os filhos.

Rapaz, eu acho que o câncer em si, eu acho que ele é muito assim devastador é um destruidor de lares de família, eu acho isso. Ai tipo, ele tenta matar as esperanças das pessoas né, ele modifica uma família tipo ele muda a vida do ser humano, você vive agora para o tratamento do filho. (Anis)

Triste, não consigo aceitar e acho que não vou vencer. Acho que vai, que vou desistir... Não é desistir, mas dá um desânimo de vez em quando porque é muitas e muitas lutas e a gente ver perdendo as outras pessoas e a gente olhando pergunta: qual vai ser o próximo? Então dá um desânimo. (Camélia)

Um papel importante do acompanhante é de manter o laço social, uma ligação com a vida além da doença.
Os participantes ressaltaram que se aproximaram mais dessas crianças/adolescentes após o diagnóstico e ao serem questionados sobre como era essa relação antes e atualmente, encontramos depoimentos apontando mudanças positivas resultantes na relação entre eles.

Antes eu era bem distante dela, eu trabalhava em São Paulo e ela ficava com meus pais. Depois que ela adoeceu, eu fico com ela agora o tempo todo... Então nossa proximidade era bem longe, agora que a gente está bem juntas, mas antes era bem longe, pouco contato. (Camélia)

Bom... Antes da doença era assim, a gente não era muito assim apegada igual é hoje. Mas agora que ela está assim a gente fica só juntas sabe, porque só eu cuido dela. Em casa, também eu fico junto dela porque eu não trabalho mais, aí fico o dia todo em casa com ela. Aí tipo que a doença aproximou a gente mais, sabe? (Flor de Lis)

Através dos relatos dos pais das crianças e adolescentes com câncer é possível compreender como eles reagiram durante todo o processo de adoecimento. Após o impacto de receber o diagnóstico esses acompanhantes sentem a necessidade de reagir e tentarem ser fortes a fim de se adaptarem a esta nova realidade, demonstrando o conformismo mesmo não aceitando a doença e assim passam a dedicar cuidado e esforço a seus filhos, tentando sempre dar o seu melhor, para que enfrentem essa situação da maneira menos dolorosa possível (Instituto Nacional do Câncer, 2020b).

Sim, foi um choque muito grande para mim quando eu descobrir que ele estava com essa doença, mas agora já estou mais aliviada, mas quando eu lembro do início isso me dá uns calafrios, mas estou muito aliviada agora. (Lírio)

Muitos referiram também utilizar a crença em Deus como uma forma de superar as dificuldades encontradas durante o tratamento. A fé, para os acompanhantes, tem um importante papel no equilíbrio emocional e na aceitação da doença, proporcionando força para continuar lutando (Duarte et al., 2012). Porém, devido as adversidades que são expostos alguns acompanhantes, em determinado momento, 
acabam por hesitar de sua fé e se sentirem, de certa forma, injustiçados. Como podemos ver neste relato:

Minha filha, logo no momento foi desesperador sabe, eu me acabei, eu me destruir, eu me lamentei, eu chorei, xinguei até a Deus. Mas ai depois eu pedi perdão a Deus, porque eu falei que Deus não existia, falei um bocado de bobagem... E estou ai lutando pela vida da minha filha que está cada dia mais difícil, mas estou firme e forte. (Flor de Lis)

O diagnóstico e início do tratamento são os momentos mais difíceis, pois o contato inicial com a doença gera nos pais receio do desconhecido, sendo acompanhados de intenso sofrimento e dor. Felizmente graças aos avanços científicos nas últimas décadas, surge a possibilidade de remissão da doença (Alves et al., 2016). Os pais que vivenciam essa possibilidade esperançosa relatam que se sentem exultantes e abençoados. Percebemos em alguns relatos que 0 momento mais triste durante o tratamento foi receber o diagnóstico e o mais feliz, após receber a notícia da remissão do câncer:

O momento mais triste foi quando eu descobri que ela tava doente, porque foi difícil... pra gente saber né que ela ia sair dessa. Porque todos os dias os médicos falavam que ela não ia sobreviver e que não sei o que.

Mas hoje pra mim está sendo feliz porque eu estou vendo que ela foi curada graças a Deus! E hoje ela tá aí prova viva para quem não acredita né. (Girassol)

O mais triste foi quando descobrir que ele estava com câncer. E o mais feliz quando descobrir que ele estava curado né? Fez já o teste do líquor e a médica disse que ele não tem mais nada. (Rosa)

A rotina e a participação dos acompanhantes no tratamento do câncer infanto-juvenil, geralmente é muito hostil e exaustiva, pois cuidar de uma criança com câncer exige tempo e dedicação. É interessante notar que a grande maioria dos acompanhantes entrevistados é constituído por mulheres. Partindo do pressuposto histórico que é da mãe, a responsabilidade pelo cuidado integral dos filhos, estas acreditam que seja sua obrigação participarem do tratamento como podemos evidenciar nas falas dos participantes a obrigatoriedade de assumir tal papel (Quintana et al., 2011). Em contrapartida, porém em minoria, alguns pais também se dedicam ao tratamento dos seus fiIhos como podemos ver nos relatos a seguir:
Como mãe, é bom para ele, ele fica mais seguro. Acho que ele tem mais apoio com a mãe do que com as outras, com as tias ele não quer ficar, com a tia nem a prima, nem com o pai mesmo ele não quer ficar.

(Orquídea)

Ah, eu descrevo assim como minha obrigação sabe? Minha obrigação de mãe, e eu vou lutar por ela e com ela até o fim. (Flor de Lis)

O pessoal até fala que nunca viu um pai igual eu, mas primeiramente a gente né, é Deus mesmo que dá forças pra gente e por eu ser o pai a gente tem que fazer de tudo até o último segundo que tiver de vida, mas tem que fazer tudo que for possivel para lutar para ver o filho sã. Assim, então eu levo ele para o Hospital todo dia de consulta, todos exames... (Cravo)

O tratamento fisioterapêutico é essencial para crianças e adolescentes com câncer, tanto na melhora da sintomatologia quanto da qualidade de vida, tendo como objetivos principais preservar, manter e restaurar a integridade cinético-funcional de órgãos e sistemas, bem como prevenir os distúrbios causados pelo tratamento da doença. Além do tratamento fisioterapêutico é necessário a realização da estimulação motora para obtenção de um melhor prognóstico (Silva, Cardoso et al., 2019). Compreendendo isto a maioria dos acompanhantes relataram participar do tratamento fisioterapêutico dos seus filhos, manterem uma rotina de estimulação motora na casa de apoio e o quanto se sentem satisfeitos com isso.

Eu faço os exercícios com ela durante o banho, quando ela acorda, antes dela dormir eu faço algumas coisas com ela também que ela faz na fisioterapia. Eu estimulo ela a ela mesmo se "lavar" né? Movimentar os braços lavando de um lado e do outro lado, entendeu?

os pés dela peço para ela tentar passar a mão onde ela consegue, tipo assim no banho. Na cama coloco ela para sentar, sento e posiciono os pés dela no chão, faço os passinhos e vou estimulando. (Margarida)

Eu no primeiro dia que eu vim né, conversar o que precisava, fazer a ficha e vim trazer ele e ele aqui é bem recebido e pra mim é uma maravilha porque se fosse para mim sair daqui para mim outro lugar para fazer fisioterapia não era fácil. Aqui não, aqui eu saio do segundo andar para o quarto andar, estou em casa.

(Cravo) 
Quando questionados sobre as mudanças que ocorreram em suas vidas após se tornarem acompanhantes de uma criança em tratamento oncopediátrico, constata-se que o adoecimento da criança ou adolescente leva à diversas alterações no cotidiano familiar como o abandono de atividade profissional, da convivência com familiares, devido a internação por tempo prolongado em casa de apoio e na maioria das vezes, concomitantemente à separação em relação aos outros filhos. Deve ser considerada também a distância de casa, pois, isto afeta os acompanhantes não apenas pelo apego emocional com os familiares que permanecem longe ou pelo conforto próprio de seus lares de que precisaram abdicar, mas também pela nova realidade que se impõe em suas vidas, a adaptação à nova cidade e o abandono de seus pertences, de seus costumes e de sua vida cotidiana (Wakiuchi et al., 2017).

Tudo. Rotina, mudou de ambiente, esse deslocamento né? já vai fazer um ano que a gente está aqui, bem na verdade e mudou tudo, o jeito de pensar, mudou a nossa visão, mudou tudo. (Margarida)

O irmão sadio percebe que o diagnóstico de câncer provoca inúmeras mudanças na família, limitando os encontros e a participação de todos juntos durante o tratamento, o que só é recompensado ao final com a cura e a reorganização familiar.

Muitas... muitas, como deixar os outros filhos em casa sozinho, sem mim, liga para mim dizendo que está com saudades também, o coração aperta. (Orquídea)

Minha vida parou tudo, eu não pude mais educar minha filha, não pude participar do crescimento dela durante esses dois anos. Não, não tenho mais uma casa, não tenho mais uma cama, ou estou no ônibus ou estou aqui ou estou no hospital. Desculpa porque eu chorei, mas é difícil. (Tulipa)

A família é o primeiro grupo social mais importante na vida do indivíduo, sendo também a primeira que, diante de uma necessidade individual de seus membros, volta-se para atender suas necessidades (Duarte et al., 2012).

Aqui na casa de apoio para mim é só agradecer, só tenho a agradecer né, só tenho a agradecer todo mundo aqui... Na fisioterapia mesmo nós gosta muito da equipe, de coração mesmo... Todo mundo atende a gente bem, eu só tenho a agradecer, primeiramente à
Deus e essa casa aqui que não só para mim mas para todos que estão passando esse tratamento aqui com os

filhos... (Cravo)

Em relação à qualidade de vida desses acompanhantes no aspecto psicológico, observou-se nesse estudo que alguns dos participantes afirmaram não aproveitar a vida ou aproveitá-la muito pouco. Os participantes deste presente estudo afirmaram que houveram mudanças na rotina, referindo que elas são provenientes do esforço em cuidar das diversas áreas da vida que se encontram afetadas.

Tudo. Eu tive que deixar minha vida para trás para viver a dela, então tudo. O que eu fazia antes... namorar, ir em festa, ter minha vida, tipo, minha vida própria, trabalhar, não tenho mais... Isso tudo ficou para trás que a gente não tem tempo. Quando a gente

vai em casa é dois dias e volta, então não tem mais namoro não tem mais nada, poucas amizades porque só fica a de verdade e acabou. (Camélia)

Tudo. Mudou em tudo a minha vida, porque eu vivo só para ele, eu não tenho tempo para mim. Aí depois que ele melhorou mais eu comecei a me arrumar, me cuidar melhor, mais nunca mais fiz uma consulta; um exame... A gente não tem mais tempo para a gente; só vivemos para o filho, é do hospital para o GACC e as vezes no hospital direto, eu já passei 3 meses com ele só internado, não tem tempo para gente! É difícil. (Lírio)

\section{Discussão}

Dentre os membros da família, normalmente, são as mães que acompanham o processo de tratamento da criança/adolescente (Cheron \& Pettengill, 2011), pois elas geralmente priorizam o cuidado e para cuidar, se organizam, fazem arranjos internos, deixam de realizar outras atividades, solicitam ajuda, em geral assumem o controle do cuidado cotidiano aos filhos, especialmente nos casos de doença.

Em relação a idade média dos acompanhantes e o estado civil, foi possível observar no estudo de Benedetti et al. (2015) que a maioria das participantes eram casadas com idades variando entre 21 e 74 anos. No estudo de Silva, Barros et al. (2011), comprovou-se a mesma informação, que a maioria das participantes era casada, com idade média de 33 anos, adverso com os achados do atual estudo. 
A casa de apoio possui grande importância, pois sem elas muitas crianças não teriam acesso adequado ao tratamento devido a condição financeira das famílias e a ausência de uma rede de assistência à saúde local onde estes residem (Sélos et al., 2014). De acordo com o estudo de Ferreira et al. (2015), eles expressaram que a hospedagem na casa de apoio auxilia no enfrentamento do tratamento, ou ainda, ameniza a difícil realidade vivenciada, o que proporciona a qualidade de vida ao sujeito hospedado. Isso se dá pelo alcance de outras características essenciais aos indivíduos, como o auxílio da família, uma dieta nutricional adequada, domínio das emoções, tranquilidade, respeito com seus princípios e história entre outros aspectos.

Sélos et al. (2014) indicaram que viver em uma casa de apoio durante o tratamento de seu filho, implica em conviver com pessoas diferentes, que vieram de diversos lugares, com costumes e formas de viver ímpares e nem sempre essas diferenças são vistas como um fator positivo.

$\mathrm{Na}$ literatura, foi encontrado um estudo (Kohlsdorf \& Costa, 2008) que descreve sobre a sobrecarga na vida do cuidador, relacionado a necessidade de deslocamento de uma cidade para outra para realização do tratamento do câncer como também desvios de recursos que seriam antes utilizados para despesa familiar. Adaptar-se a essa nova situação é um desafio para o cuidador podendo lhe causar estresse físico, emocional, psicológico e também financeiro, pois o filho doente passa a se tornar o centro de sua vida (Almico \& Faro, 2014). Desta maneira, a doença e hospitalização da criança alteram a dinâmica familiar, conduzindo a diferentes sentimentos e emoções, como medo, impotência e culpa, onde muitas vezes a pessoa que acompanha a criança no hospital precisa enfrentar sozinha a dificuldade, sentindo-se abandonada e até mesmo esquecida pela família (Instituto Nacional do Câncer, 2020b).

A confirmação do diagnóstico de câncer muda drasticamente a vida do portador da doença e de seus familiares. Não apenas pela notícia, mas principalmente pelas implicações oriundas do tratamento. Além disto as dúvidas e questionamentos que surgem sobre o câncer pode ser, de certa forma, uma barreira, levando em conta que alguns acompanhantes possuem pouco ou nenhum conhecimento prévio sobre a doença (Farinhas et al., 2013).
Dentre os principais fatores relacionados ao atraso no diagnóstico inclui-se o nível de educação dos pais. Ressalta-se que o atraso no diagnóstico colabora para aumento do período entre o início da doença e seu tratamento correto, o que pode acabar refletindo na evolução da doença (Fermo et al., 2014) (Tabela 1).

Diante dos estudos Duarte et al. (2012); Ferreira et al. (2015) é possível observar que a leucemia está entre os tipos de câncer mais comuns em crianças/adolescentes e em sequência, os tumores do Sistema nervoso central e de partes moles.

O tratamento do câncer gera efeitos colaterais desagradáveis na criança/adolescente, causando-lhes sofrimento e exaustão (Instituto Nacional do Câncer, 2020b). Com objetivo de atingir células malignas, impedindo sua multiplicação por mitose e/ou determinando a morte celular temos como formas de tratamento a quimioterapia e a radioterapia. A quimioterapia antineoplásica é amplamente utilizada no tratamento do câncer e consiste no emprego de substâncias químicas, isoladas ou em combinação, já a radioterapia é a modalidade terapêutica que utiliza as radiações ionizantes no combate aos agentes neoplásicos podendo estas serem combinadas para assim potencializar seus efeitos (Instituto Nacional do Câncer, 2020a).

Quanto maior a informação e o envolvimento das mães no plano terapêutico da criança, esclarecendo os riscos/benefícios, maior o entendimento, segurança e tranquilidade para a adesão ao tratamento proposto (Farinhas et al., 2013). Além disso, a compreensão da doença por parte dos pais possibilita maior envolvimento nos cuidados, acompanhamento do tratamento, redução da ansiedade e cooperação com a equipe (Sales et al., 2012).

Para enfrentar o câncer, os acompanhantes buscam força e coragem na religiosidade, em que elas tentam encontrar explicação/sentido para o adoecimento do seu filho e ao mesmo tempo a esperança de obterem a cura. No estudo de Almico e Faro (2014), foi citado que quando a família não perde a fé e consegue seguir em frente, mesmo diante do sofrimento, buscam ter a religião como uma aliada na luta contra a grave doença. Enfim, considerando a importância da fé como um elemento de suporte emocional os cuidadores em situações de adoecimento de seus fiIhos, acredita-se ser fundamental compreender essa experiência em seu sentido particular e singular na 
tentativa de desenvolver modos mais saudáveis de lidar com o sofrimento desencadeado pelo tratamento (Instituto Nacional do Câncer, 2020b).

O relacionamento entre fisioterapeuta e paciente é um fator fundamental para o sucesso da reabilitação, além de ser peça-chave no processo de adesão. No caso dos fisioterapeutas, fatores relacionados à qualidade do relacionamento e às habilidades sociais do terapeuta aparecem como prioritários, inclusive em relação às habilidades técnicas. É de grande importância o estabelecimento de vínculos entre o profissional e a família, e o vínculo que se constrói entre esses indivíduos deve ser permeado por atenção, conforto e carinho (Schwertner et al., 2021). Sendo essencial para estes acompanhantes sentirem-se motivados a levar seus filhos para fisioterapia.

O paciente que realiza o tratamento longe de seu lar encontra-se muitas vezes em situação de dependência para alcançar a satisfação do dia a dia devido às exigências do tratamento, assim este amparo ofertado pela casa possui valor imensurável para estes indivíduos que o recebem (Dossena \& Perez, 2017). A atenção humanizada que contempla o carinho, a atenção e a conversa torna-se ferramenta fundamental no enfretamento da doença. O estudo de Silva, Barros et al. (2011) confirma que houve mudanças na rotina desses familiares, pois muitos acompanhantes deixaram de trabalhar, estudar, abriram mão do seu lazer e do cuidado com a sua própria saúde por se dedicarem integralmente ao cuidado da saúde com seus filhos.

Problemas de ordem emocional ocorrem com frequência tanto em pacientes com câncer como em seus familiares em função da dificuldade em lidar com o diagnóstico. Não raro, transtornos psicológicos como depressão e ansiedade são diagnosticados no paciente e em seus familiares em todas as fases do tratamento (Silva, Barros et al., 2011). Em alguns momentos, as consequências sociais e psicológicas do câncer infantil podem ser mais debilitantes que a própria doença física. Para os familiares assumirem a posição de cuidadores da criança de maneira plena, eles precisam desfrutar de boas condições que os capacitam a se envolverem no enfrentamento da doença. Entretanto, os familiares, frequentemente, se deparam com a situação de procurarem poupar a criança, sobrecarregando eles mesmos com um sofrimento psíquico que repercute por toda a organização familiar (Alves et al., 2016).

\section{Considerações finais}

Os participantes da pesquisa foram compostos em sua maioria pelo sexo feminino, solteiros, possuindo outros filhos, sendo a mãe a principal acompanhante do tratamento. Com a necessidade de deixar o emprego para cuidar da criança a maioria dos acompanhantes não desempenham nenhum tipo de ocupação. Como residem distante da unidade de atendimento, a oportunidade de permanecer numa casa de apoio facilita o acesso ao tratamento, pois em muitos casos as famílias não possuem condições financeiras para os gastos com viagens e hospitalizações.

Nesse momento tão delicado, a fé é um valioso elemento para o suporte emocional dos acompanhantes na tentativa de desenvolver modos mais saudáveis de lidar com o sofrimento desencadeado pelo tratamento. Devido a rotina hospitalar necessária para realização do tratamento dos pacientes, a limitação encontrada no presente estudo foi conciliar a presença dos acompanhantes na casa de apoio com a realização das entrevistas. Diante do sofrimento emocional identificado na fala dos acompanhantes, sugere-se acompanhamento multiprofissional adequado a fim de que possam expor suas angústias, receios e dificuldades. Assim, ressaltamos o valor deste estudo em contribuir na disseminação do conhecimento científico para as áreas de Fisioterapia pediátrica, oncologia e o cuidado do acompanhante durante $o$ adoecimento.

\section{Contribuições dos autores}

Bulcão HFB, Alcântara JM e Mota LMR elaboraram o projeto inicial, que foi revisado por Ferraz PCS. Bulcão HFB participou da escrita, formatação do artigo, interpretação dos resultados, análise estatística e revisão do texto. Alcântara JM foi responsável pela escrita, coleta de dados, interpretação dos resultados, análise estatística e revisão do texto. Barbosa LO participou da escrita, supervisão da coleta de dados e revisão do texto. Mota LMR participou da escrita, tradução do manuscrito, interpretação dos resultados, análise estatística e revisão do texto. Ferraz PCS foi responsável pela escrita, revisão intelectual crítica do manuscrito, análise estatística, revisão do texto e orientou o trabalho. Todos os autores leram e aprovaram a versão final do manuscrito. 


\section{Conflitos de interesses}

Nenhum conflito financeiro, legal ou político envolvendo terceiros (governo, empresas e fundações privadas, etc.) foi declarado para nenhum aspecto do trabalho submetido (incluindo, mas não se limitando a subvenções e financiamentos, participação em conselho consultivo, desenho de estudo, preparação de manuscrito, análise estatística, etc.).

\section{Referências}

Almico, T., \& Faro, A. (2014). Enfrentamento de cuidadores de crianças com câncer em processo de quimioterapia. Psicologia, Saúde \& Doenças, 15(3), 723-737. https://dx.doi. org/10.15309/14psd150313

Alves, K. M. C., Comassetto, I., Almeida, T. G., Trezza, M. C. S. F., Silva, J. M. O., \& Magalhães, A. P. N. (2016). A vivência dos pais da criança com câncer na condição de impossibilidade terapêutica. Texto \& Contexto - Enfermagem, 25(2), e2120014. https://doi. org/10.1590/0104-07072016002120014

Benedetti, G. M. S., Higarashi, I. H., \& Sales, C. A. (2015). Vivências de pais/mães de crianças e adolescentes com câncer: uma abordagem fenomenológico-existencial Heideggeriana. Texto \& Contexto - Enfermagem, 24(2), 554-562. https://doi. org/10.1590/0104-07072015002702014

Cheron, M. F. L., \& Pettengill, M. A. M. (2011). Experiência do irmão sadio em relação à doença e hospitalização do irmão com câncer. Acta Paulista de Enfermagem, 24(5), 605610. https://doi.org/10.1590/S0103-21002011000500002

Cicogna, E. C., Nascimento, L. C., \& Lima, R. A. G. (2010). Crianças e adolescentes com câncer: experiências com a quimioterapia. Revista Latino-Americana Enfermagem, 18(5), 9. https://www.scielo.br/j/rlae/a/ PwZfZ37N3T6dBJQtHrg7jgw/?format=pdf\&lang=pt

Dossena, D. T., \& Perez, K. V. (2017). Importância da casa de acolhida para pessoas com diagnóstico de câncer. VI Jornada de Pesquisa em Psicologia - PSI UNISC: Pesquisa e Tecnologia na Psicologia Atual, 2237-9207. https://online. unisc.br/acadnet/anais/index.php/jornada_psicologia/ article/view/17630

Duarte, M. L. C., Zanini, L. N., \& Nedel, M. N. B. (2012). O cotidiano dos pais de crianças com câncer e hospitalizadas. Revista Gaúcha de Enfermagem, 33(3), 1983-1447. https://doi. org/10.1590/S1983-14472012000300015
Farinhas, G. V., Wendling, M. I., \& Dellazzana-Zanon, L. L. (2013). Impacto psicológico do diagnóstico de câncer na família: um estudo de caso a partir da percepção do cuidador. Pensando famílias, 17(2), 111-129. http://pepsic. bvsalud.org/scielo.php?script=sci_arttext\&pid=S1679494X2013000200009

Fermo, V. C., Lourençatto, G. N., Medeiros, T. S., Anders, J. C., \& Souza, A. I. J. (2014). O diagnóstico precoce do câncer infantojuvenil: o caminho percorrido pelas famílias. Escola Anna Nery, 18(1), 54-59. https://doi.org/10.5935/14148145.20140008

Ferreira, P. C., Wakiuchi, J., Baldissera, V. D. A., \& Sales, C A. (2015). Sentimentos existenciais expressos por usuários da casa de apoio para pessoas com câncer. Escola Anna Nery, 19(1), 66-72. https://doi.org/10.5935/1414-8145.20150009

França, J. R. F. S., Silva, E. C., Machado, K. O. A., Oliveira, T. C., Silva, M. F.O.C., \& Freire, M.E.M. (2017). Vivência de crianças com câncer sob assistência paliativa em uma casa de apoio. Revista Mineira de Enfermagem, 21(1065), 1-8. http://dx.doi. org/10.5935/1415-2762.20170075

Gomes, A. M. T. (2015). Análise de discurso francesa e teoria das representações sociais: algumas interfaces teóricometodológicas. Psicologia e Saber Social, 4(1), 3-18. https:// doi.org/10.12957/psi.saber.soc.2015.17558

Instituto Nacional de Câncer José Alencar Gomes da Silva (2020a). ABC do câncer: abordagens básicas para o controle do câncer (6. ed. rev. atual.). Instituto Nacional de Câncer José Alencar Gomes da Silva. https://www.inca.gov.br/sites/ufu. sti.inca.local/files/media/document/livro-abc-5-edicao.pdf

Instituto Nacional do Câncer José Alencar Gomes da Silva (2020b, dez). Incidência, mortalidade e morbidade hospitalar por câncer em crianças, adolescentes e adultos jovens no Brasil. https://www.inca.gov.br/publicacoes/livros/ incidencia-mortalidade-e-morbidade-hospitalar-porcancer-em-criancas-adolescentes

Instituto Nacional do Câncer José Alencar Gomes da Silva (2021, agosto). Como surge o câncer? https://www.inca.gov.br/ como-surge-o-cancer

Kohlsdorf, M., \& Costa Junior, Á. L. (2008). Estratégias de enfrentamento de pais de crianças em tratamento de câncer. Estudos de Psicologia (Campinas), 25(3), 417-429. https://doi.org/10.1590/S0103-166X2008000300010

Kohlsdorf, M., \& Costa Junior, Á. L. (2011). Cuidadores de crianças com leucemia: exigências do tratamento e aprendizagem de novos comportamentos. Estudos de psicologia, 16(3), 1678-4669. http://dx.doi.org/10.1590/S1413294X2011000300004 
Ministério da Saúde. (2019, jul 28). Protocolo de Diagnóstico Precoce do Câncer Pediátrico. https://bvsms.saude.gov.br/ bvs/publicacoes/protocolo_diagnostico_precoce_cancer pediatrico.pdf

Quintana, A. M., Wottrich, S. H., Camargo, V. P., Cherer, E. Q., \& Ries, P. K. (2011). Lutos e lutas: Reestruturações familiares diante do câncer em uma criança / adolescente. Psicologia Argumento, 29(65), 143-154. https://periodicos.pucpr.br/ index.php/psicologiaargumento/article/view/20035

Sales, C. A., Benedetti, G. M. S., Santos, J. A., \& Marcon, S. S. (2012). O impacto do diagnóstico do câncer infantil no ambiente familiar e o cuidado recebido. Revista Eletrônica de Enfermagem, 14(4), 841-849. https://doi.org/10.5216/ ree.v14i4.15446

Schwertner, M. V. E., Nietsche, E. A., Salbego, C., Pivetta, A., Silva, T. C., \& Stochero, H. M. (2021). Estratégias de auxílio a famílias no enfrentamento do pós-diagnóstico de câncer infantil. Revista De Pesquisa Cuidado é Fundamental Online, 13, 443-450. http://dx.doi.org/10.9789/2175-5361.rpcfo. v13.7543
Sélos, P. R., Costa, P. C. P., \& Toledo, V.P. (2014). Vivendo em casa de apoio durante o tratamento do câncer infantil: percepções maternas. Revista de Enfermagem UFPE, 8(6), 1474- 81. https://periodicos.ufpe.br/revistas/ revistaenfermagem/article/view/9835

Silva, T. C. O., Barros, V. F., \& Hora, E. C. (2011). Experiência de ser um cuidador familiar no câncer infantil. Rev Rene, 12(3), 526-531. http://periodicos.ufc.br/rene/article/ view/4276/3297

Silva, A. R., Cardoso, L. F., \& Oliveira, F. T. C. (2019). Análise do conhecimento da fisioterapia oncológica pelos acadêmicos do curso de fisioterapia de uma faculdade privada no município de Trindade-GO. Vita et Sanitas, 13, 169-80. http://fug.edu.br/revistas/index.php/ VitaetSanitas/article/view/189

Wakiuchi, J., Benedetti, G. M. S., Casado, J. M., Marcon, S. S., \& Vendas, C. A. (2017). Sentimentos compartilhados por acompanhantes de pacientes com câncer hospedados em albergues: um estudo fenomenológico. Escola Anna Nery, 21(1), e20170011. https://www.scielo.br/j/ean/a/ BrkqqLqfWZMQVjQBypFXGcr/abstract/?lang=pt 